Haftom Niguse người bệnh dùng cả insulin và thuốc uống hạ đường huyết có kiến thức không đạt yêu câuu gấp 0,06 lân so với nhóm dùng insulin [7]. Điều này có thể lý giải việc sử dụng nhiều loại thuốc trong điều trị người bệnh sẽ nhận được nhiều thông tin tư vấn hướng dẫn sử dụng thuốc, kiểm soát đường huyết tốt hơn do đó kiến thức tự chăm sóc của người bệnh cũng tốt hơn.

Để đánh giá chính xác mức độ ảnh hưởng của các biến có liên quan đến kiến thức tự chăm sóc chúng tôi đã thực hiện kiểm định Logistic và mô hình hồi quy đa biến giúp chúng ta nhìn tổng quát và chính xác hơn mức độ ảnh hưởng của các biến độc lập đến biến mức độ kiến thức tự chăm sóc. Mô hình đã tìm ra các biến: trình độ học vấn, thời gian mắc bệnh, thuốc điêu trị đái tháo đường của người bệnh có liên quan đến kiến thức tự chăm sóc của người bệnh và có thể dự báo chính xác tới 68,3\% (Bảng 3)

\section{KẾT LUẬN}

Tỷ lệ người bệnh chưa có kiến thức tốt về tự chăm sóc chiếm $41,3 \%$, với điểm trung bình của các nội dung về tự chăm sóc đạt 20,25 \pm 3,49 trên tổng điểm 30, trong đó chủ yếu là thiếu kiến thức về kiểm soát đường máu. Trong giai đoạn Covid-19, kiến thức của người bệnh liên quản có ý nghĩa thống kê $(p<0,05)$ với trình độ học vấn OR = 10,6 (95\% CI: 4,5-25,0); thời gian mắc bệnh $\mathrm{OR}=4,7(95 \% \mathrm{CI}: 2,3-9,6)$; thuốc đang điêu trị là dạng uống/insulin với $\mathrm{OR}=3,1$ (95\% CI: 1,4-6,9).

\section{TÀI LIÊU THAM KHẢO}

1. Internation Diabetes Federation (2019). IDF Diabetes Atlas 9th edition 2019. Brussels, 212-215.

2. Federation International Diabetes IDF Clinical Practice Recommendations for managing Type 2 Diabetes in Primacy Care. Internation Diabetes Federation, 8, 1-43.

3. Kassahun T, Gesesew H, Mwanri L. (2016). Diabetes related knowledge, self-care behaviours and adherence to medications among diabetic patients in Southwest Ethiopia: a cross-sectional survey, BMC Endocr Disord, 16(1), 28.

4. Nguyễn Vũ Huyền Anh (2016), Đánh giá kiến thức tự chăm sóc của người bệnh đái tháo đường type 2 tai bênh viện đa khoa tỉnh Điên Biên năm 2016, Luận văn thạc sỹ điêu dưỡng, Đại Hoc Điều dương Nam Định.

5. Nguyễn Thị Thắm (2017), Thực trạng kiến thức và thực hành phòng biến chứng cưa người bênh đái tháo đường típ 2 điều trị ngoai trú tai Bểnh viện đa khoa Thành Phố Hà Tĩnh nằm 2017, Luận văn thạc sỹ điều dưỡng, Đại Hoc Điều dưỡng Nam Định, Nam Định.

6. Rahaman Kh.S, Majdzadeh R, Holakouie Naieni K. (2017). Knowledge, Attitude and Practices (KAP) Regarding Chronic Complications of Diabetes among Patients with Type 2 Diabetes. Int J Endocrinol Metab

7. Niguse H, Belay G, Fisseha G.(2019). Self-care related knowledge, attitude, practice and associated factors among patients with diabetes in Ayder Comprehensive Specialized Hospital, North Ethiopia. BMC research notes, 12(1), 1-7.

\title{
NGHIÊN CỨU TÁC DỤNG CỦA NHĨ ẤP KÊTT HỢP PHƯƠNG PHÁP LUYÊ̂N THỞ DƯỠNG SINH NGUYỄN VĂN HƯỞNG VÀ TƯ VẤN TRONG ĐIỀU TRỊ CAI NGHIỆN THUỐC LÁ
}

\section{TÓM TẮT}

Mục tiêu: Đánh giá tác dụng điều trị Hội chứng cai trong cai nghiện thuốc lá của phương pháp nhĩ áp kết hợp phương pháp luyện thở dưỡng sinh Nguyễn Văn Hưởng và tư vấn, theo dõi tác dụng không mong muốn của phương pháp can thiệp. Đối tượng và phương pháp: thử nghiệm lâm sàng tiến cứu, so sánh trước và sau điều trị. Đối tượng là 140 bệnh nhân. Liệu trình điều trị là 28 ngày. Khi hết liệu trình tiếp tục theo dõi quan sát bệnh nhân thêm 1 tháng,

*Bêenh viện Y học cổ truyền Trung ương

Chịu trách nhiệm chính: Trân Thái Hà

Email: phdtranthaiha@gmail.com

Ngày nhận bài: 13.9.2021

Ngày phản biện khoa học: 9.11 .2021

Ngày duyệt bài: 16.11.2021

\section{Trần Thái Hà*, Đào Hữu Minh*}

thêm 2 tháng để đánh giá hiệu quả của phương pháp can thiệp Kết quả: Cai nghiện thuốc lá đạt tỷ lệ $57.2 \%$ tốt, $16.4 \%$ khá và $26.4 \%$ không kết quả. Kết quả sau điêu trị 2 tháng không có sự thay đổi với tỉ lệ là $73.6 \%$ người không còn hút thuốc, sau điều trị 3 tháng tỉ lệ người không còn hút thuốc là $72,1 \%$. Kết luận: Nhî̉ áp kết hợp phương pháp luyện thở dưỡng sinh Nguyễn Văn Hưởng và tư vấn có tác dụng cai nghiện thuốc lá, cải thiện các triệu chứng của Hội chứng cai: thèm thuốc, İo lắng,căng thẳng, cáu gắt, giảm tập trung, tăng cân... và làm giảm hàm lượng CO trong hởi thở của bệnh nhân sau cai nghiện thuốc lá.

Ti̛ khóa: Cai nghiện thuốc lá, Hội chứng cai, nhĩ áp, luyện thở dưỡng sinh, tư vấn

\section{SUMMARY \\ STUDY THE EFFICIENCY OF SMOKING}




\section{CESSATION THROUGH THE COMBINATION BETWEEN AURICULAR POINT ACUPRESSURE, BREATHING PRACTICE METHOD AND MEDICAL ADVICE}

Objectives: To determine the effectiveness of auricular point acupressure, breathing practice method and giving medical advice in smoking cessation treatment and monitor methods' adverse reaction. Subjects and Methods: Perspective clinical trial, comparisons of before and after treatment. There are 140 patients in the 28-day treatment. At the end of the course, we continue to monitor and observe the patient for 1 more month, and evaluating the effectiveness of the method for the next 2 months. Results: The very good rate of smoking cessation cases were $57,2 \%, 16.4 \%$ of these were good and $26.4 \%$ of these were not effective. Results after 2 months of treatment did not change with the rate of $73.6 \%$ of people who have no longer smoked and the rate of these was $72.1 \%$ after 3 months of treatment. Conclusions: Auricular point acupressure, breathing practice method and medical advice is effective in smoking cessation, improving symptoms of withdrawal syndrome (shortness, irritability, insomnia, cravings ...) and decreased levels of $\mathrm{CO}$ in the breath of patients after treatment.

Keywords: Smoking cessation, withdrawal syndrome, auricular point acupressure, breathing pratice method, medical advise

\section{I. ĐĂT VẤN ĐỀ}

Thuốc lá là một trong những mối đe dọa sức khỏe cộng đồng lớn nhất mà thế giới phải đối mặt, giết chết hơn 8 triệu người mỗi năm trên toàn thế giới. Trong đó có hơn 7 triệu ca tử vong này là kết quả của việc sử dụng thuốc lá trực tiếp và khoảng 1,2 triệu ca tử vong do hút thuốc lá thụ động [1]. Tại Việt Nam, theo thống kê điều tra tình hình sử dụng thuốc lá ở người trưởng thành (GATS 2015), đã cho thây có 22,5\% dân số trên 15 tuổi đang hút thuốc lá, tương đương với 15,6 triệu người[2].

Trong thuốc lá có khoảng 7000 chất hóa học, trong đó có 250 chất gây hại và ít nhất 69 chất gây ung thư [3][4][5] và đặc biệt có nicotin một chất gây nghiện quyết định sự phụ thuộc và chống lại các cố gẳng bỏ thuốc lá. Thuốc lá còn gây ra các bệnh lý mạn tính trầm trọng khác như đột quy,, nhồi máu cơ tim, bệnh phổi tắc nghẽn mạn tính hay ung thư.

Trước những tác hại về kinh tế xã hội cũng như sức khỏe, đã có hàng loạt chương trình phòng chống tác hại của thuốc lá ở trong nước và trên thế giới nhằm kiểm soát và giảm tỷ lệ hút thuốc. Nhiều phương pháp cai nghiện thuốc lá của $Y$ học hiện đại như: viên dán nicotine, laser, tâm lý liệu pháp...

Y học cổ truyền cũng có nhiều đóng góp tích cực vào công tác phòng chống cai nghiên thuốc lá. Nhiều phương pháp điều trị cai nghiện thuốc lá được sử dung như: nhĩ châm, châm cứu, xoa bóp bấm huyệt, tập luyện dưỡng sinh, thuốc thang YHCT... Tuy nhiên cho tới nay chưa có nhiêu công trình nghiên cứu đánh giá một cách đầy đủ và khoa học về tác dụng của nhĩ áp kết hợp phương pháp luyện thở dưỡng sinh Nguyễn Vằn Hưởng và tư vấn trong điều trị cai nghiện thuốc lá.

Vì vậy, chúng tôi tiến hành xây dựng nghiên cứu "Nghiên cứu tác dụng của nhĩ áp kết hợp phương pháp luyện thở dưỡng sinh Nguyễn Vằn Hưởng và tư vấn trong điều trị cai nghiện thuốc lá" với 2 mục tiêu:

1. Đánh giá tác dụng của phương pháp nhĩ áp kết hợp phương pháp luyện thở dưỡng sinh Nguyễn Văn Hưởng và tư vấn trong điều trị cai nghiện thuốc lá.

2. Theo dôi tác dụng không mong muốn của phương pháp can thiệp.

\section{CHẤT LIỆ, ĐỐI TƯợNG VÀ PHƯƠNG}

\section{PHÁP NGHIÊN CứU}

\subsection{Chất liệu nghiên cứu}

- Chất liệu nghiên cứu: Miếng dán nhĩ áp

Miếng dán có đường kính $5 \mathrm{~mm}$

Hộp 10 vỉ x 60 miếng dán

Sản xuất tại Thượng Hải, Trung Quốc

Han sử dụng: 2 năm

2.2. Đối tượng nghiên cứu. Gồm 140 bệnh nhân được chẩn đoán nghiện thuốc lá được điều trị tại Phòng tư vấn cai nghiện thuốc lá Bệnh viện $Y$ học cổ truyền Trung ương.

- Thời gian nghiên cứu: Từ tháng 6 năm 2020 đến tháng 12 năm 2020.

- Tiêu chuẩn chọn bệnh nhân:

- Chọn bệnh nhân nghiện thuốc lá không phân biệt giới tính, nghề nghiệp, tuổi từ 18 - 80 .

- Mức độ quyết tâm cai thuốc lá đánh giá theo bảng Q-MAT $\geq 7$ điểm.

- Tiêu chuẩn nghiện thuốc lá được chẩn đoán theo DSM - IV[6]:

- Tiêu chuẩn loại trừ:

- Các người nghiện thuốc lá mắc các bệnh truyền nhiễm cấp tính, lao, $K$, viêm gan, mắc các bệnh nặng như suy tim, suy gan, suy thận, HIV giai đoạn cuối.

- Người nghiện thuốc lá đang bị viêm nhiễm, nhiễm trùng hay chấn thương vùng tai.

- Phụ nữ có thai

- Bệnh nhân dùng thêm các phương pháp điều trị khác.

- Bệnh nhân không tuân thủ quy trình nghiên cứu. 


\subsection{Phương pháp nghiên cứu}

- Ngày đầu tiên đến khám: Người nghiện thuốc lá được khám và hỏi bệnh theo bệnh án nghiên cứu sàng loc đảm bảo cõ mẫu và phát hiện bệnh không đủ tiêu chuẩn loại khỏi nghiên cứu.

Bước 1: Tiến hành tư vấn cai nghiện thuốc lá cho người nghiện thuốc lá. Thời gian tư vấn từ 15-30 phút và cung cấp số điện thoại để hỗ trợ cai nghiện

- Đo nồng độ khí CO trong hơi thở, nhịp tim, huyết áp và làm các xét nghiệm: công thức máu, sinh hóa máu (GOT, GPT, Ure, Creatinin...), xét nghiệm nước tiểu, nội soi tai mũi họng, XQ tim phổi, điện tâm đồ, siểu âm ổ bụng.

Bước 2: Hướng dẫn bệnh nhân tự luyện tập tại nhà phương pháp luyện thở dương sinh Nguyễn Văn Hưởng.

*Luyện thở: (15 phút) ở đây chúng tôi áp dụng phương pháp thở 4 thì có kê mông và giơ chân.[7]

- Tư thế tập: Nằm ngửa, đầu không gối, kê mông cao $10-20 \mathrm{~cm}$ chân duỗi thẳng, một tay để lên ngực, một tay để lên bụng.

- Các thì thơ:

Thì một: Hít vào đều, sâu , tối đa, ngực nở, bụng phình và cứng. Thời gian bằng $1 / 4$ hơi thở tương ứng với câu "Hít vào ngực nở, bụng căng".

Thì hai: Giữ hơi, cơ hoành và lồng ngực đều co thắt tối đa, thanh quản mở, hai chân giơ thay phiên nhau cao $20 \mathrm{~cm}$. Thời gian bằng $1 / 4$ hơi thở tương ứng với câu: "Giữ hơi cố gắng hít thêm".

Thì ba: Thở ra thoải mái, tự nhiên không kìm, không thúc. Thời gian bằng $1 / 4$ hơi thở tương ứng với câu: "Thở ra không kìm không thúc".

Thì bốn: Ngừng thở, thư giãn hoàn toàn có cảm giác nặng và ấm, tự kỷ ám thị: Tay chân tôi nặng và ấm, toàn thân tôi nặng và ấm, thời gian bằng $1 / 4$ hơi thở, tương ứng với câu: "Nghĩ thời nặng ấm chân tay".

Bước 3 Điều trị bằng phương pháp nhĩ áp.

\section{KẾT QUẢ NGHIÊN CỨU}

\subsection{Sự cải thiện các triệu chứng sau bỏ thuốc lá} Bảng 3.1. Các triệu chứng sau bỏ thuốc

\begin{tabular}{|c|c|c|c|c|c|c|c|c|c|c|}
\hline & \multicolumn{3}{|c|}{$\mathbf{D 0}$} & \multicolumn{2}{c|}{$\mathbf{D 7}$} & \multicolumn{2}{c|}{$\mathbf{D 1 4}$} & \multicolumn{2}{c|}{$\mathbf{D 2 1}$} & \multicolumn{2}{c|}{$\mathbf{D 2 8}$} \\
\hline Triệu chứng & $\mathbf{N}$ & $\mathbf{0}$ & $\mathbf{n}$ & $\mathbf{\%}$ & $\mathbf{n}$ & $\mathbf{\%}$ & $\mathbf{n}$ & $\mathbf{\%}$ & $\mathbf{n}$ & $\mathbf{\%}$ \\
\hline Thèm thuốc & 116 & 82,86 & 139 & 99,3 & 122 & 87,14 & 65 & 46,43 & 36 & 25,71 \\
\hline Lo lắng & 10 & 7,14 & 15 & 10,71 & 0 & 0 & 0 & 0 & 0 & 0 \\
\hline Căng thắng & 18 & 12,86 & 63 & 45 & 20 & 14,28 & 5 & 3,57 & 0 & 0 \\
\hline Cáu gắt & 11 & 7,86 & 19 & 13,57 & 4 & 2,86 & 1 & 0,71 & 0 & 0 \\
\hline Giảm tập trung & 33 & 23,57 & 50 & 35,71 & 18 & 12,86 & 6 & 4,29 & 3 & 2,14 \\
\hline Mất ngủ & 12 & 8,57 & 23 & 16,43 & 9 & 6,43 & 2 & 1,43 & 0 & 0 \\
\hline Đau đâu & 5 & 3,57 & 5 & 3,57 & 1 & 0,71 & 0 & 0 & 0 & 0 \\
\hline Ho & 5 & 3,57 & 10 & 7,14 & 1 & 0,71 & 0 & 0 & 0 & 0 \\
\hline Ngứa họng & 8 & 5,71 & 10 & 7,14 & 1 & 0,71 & 0 & 0 & 0 & 0 \\
\hline
\end{tabular}

Công thức huyệt: 1.Thần môn; 2. Thận; 3. Phế; 4.Tâm; 5. Tỳ; 6. Miệng; 7.Dưới vỏ; 8. Giao cảm

\section{Phương thức điều trị:}

- Mỗi lần dùng 3-4 điểm gắn miếng nhĩ áp lên điểm đó. Dặn bệnh nhân khi có cảm giác thèm hút, muốn hút hoặc có cảm giác khó chịu khác khi cai thuốc thì dùng tay ấn vào điểm đã gắn miếng nhĩ áp trên loa tai của mình trong 5-10 giây.

- 7 ngày thay miếng dán 1 lần

- Hai bên loa tai thay đổi nhau dán nhĩ áp.

- Tùy thuộc vào các triệu chứng của người cai thuốc lá gặp phải mà chọn các điểm dán trên loa tai cho phù hợp.

- Liệu trình điều trị: Điều trị 28 ngày liên tục, mỗi bệnh nhân được thay miểng dán 5 lần vào các ngày: D0, D7, D14, D21, D28 và tự luyện thở bài tâp luyện thở dưỡng sinh Nguyễn Văn Hưởng mỗi ngày 15 phút trong 28 ngày tại nhà theo hướng dấn.

- Khi hết liệu trình tiếp tục theo dõi quan sát bệnh nhân thêm 1 tháng, thềm 2 tháng để đánh giá hiệu quả của phương pháp can thiệp.

\subsection{Chỉ tiêu theo dõi và đánh giá kết quả}

2.4.1. Các chỉ tiêu đánh giá kêt quả điều trị

- Lâm sàng:

+ Các dấu hiệu lâm sàng của Hội chứng cai: Theo dõi, đánh giá tại các thời điểm: D0, D7, D14, D21, D28, D60, D90.

+ Nhịp tim, huyết áp: Theo dõi tại các thời điểm: D0, D7, D14, D21, D28, đánh giá trước sau điều trị.

Đánh giá kết quả điều trị dựa trên nồng độ khí CO như sau:[8]

+ Loại tốt: nồng độ khí CO trong hơi thở 0-5 ppm

+ Loại khá: nồng độ khí CO trong hơi thở 6 10ppm

+ Không kết quả: Bệnh nhân hút thuốc trở lại: nồng độ khí $C O$ trong hơi thở $\geq 11$ ppm

2.5. Xử lý số liệu: Theo phương pháp thống kê dùng trong y sinh học SPSS 20.0 


\begin{tabular}{|c|c|c|c|c|c|c|c|c|c|c|}
\hline Tăng cân & 0 & 0 & 22 & 15,71 & 21 & 15 & 18 & 12,86 & 12 & 8,57 \\
\hline Khác & 0 & 0 & 0 & & 0 & 0 & 0 & 0 & 0 \\
\hline
\end{tabular}

Nhận xét: Qua bảng ta thấy sau khi cai thuốc lá trên 140 bệnh nhân triệu chứng hay gặp nhất ở người bệnh là thèm thuốc, lo lắng, căng thẳng, cáu gắt, giảm tập trung, tăng cân.. và các triệu chứng này sẽ giảm dần đi trong quá trình điều trị..

3.2. Sự thay đổi nhịp tim và huyết áp

Bảng 3.2 Sự thay đổi nhịp tim và huyêt áp

\begin{tabular}{|c|c|c|c|c|c|c|c|}
\hline & $\mathbf{n}$ & Ngày 0 & Ngày 7 & Ngày 14 & Ngày 21 & Ngày 28 & p D0-D28 \\
\hline Nhịp tim & 140 & $70,76 \pm 10,48$ & $70,72 \pm 9,95$ & $70,29 \pm 9,64$ & $70,76 \pm 9,16$ & $70,7 \pm 9,39$ & \\
\cline { 1 - 6 } HA tối đa & 140 & $119,89 \pm 8,27$ & $120,61 \pm 7,85$ & $120,64 \pm 7,88$ & $118,32 \pm 8,83$ & $119,11 \pm 7,87$ & $>0,05$ \\
\hline HA tối thiểu 140 & $72,96 \pm 6,59$ & $73,75 \pm 6,81$ & $73,29 \pm 6,83$ & $72,04 \pm 7,48$ & $72,57 \pm 6,85$ & \\
\hline
\end{tabular}

Nhận xét: Nhận thấy không có sự thay đổi nào có ý nghĩa thống kê trước và sau điều trị đối với các chî̉ số nhịp tim và huyết áp với $p>0.05$.

3.3. Nồng độ khí $\mathrm{CO}$ trước và sau điều trị:

Bảng 3.3. Nồng độ khí CO trước và sau điều trị

\begin{tabular}{|c|c|c|c|c|c|c|c|}
\hline 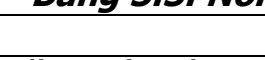 & $\mathbf{N}$ & Ngày 0 & Ngày 7 & Ngày 14 & Ngày 21 & Ngày 28 & p D0-D28 \\
\hline $\begin{array}{c}\text { Nồng độ khí CO } \\
(\mathrm{ppm})\end{array}$ & 140 & $\begin{array}{c}15,23 \pm \\
2,18\end{array}$ & $\begin{array}{c}13,56 \pm \\
2,56\end{array}$ & $\begin{array}{c}10,96 \pm \\
2,75\end{array}$ & $\begin{array}{c}8,97 \pm \\
4,04 \\
\end{array}$ & $\begin{array}{c}7,14 \pm \\
5,24 \\
\end{array}$ & $<0,05$ \\
\hline P sau 7 ngày & & & & $<0,05$ & & & \\
\hline
\end{tabular}

Nhận xét: Dựa vào kết quả bảng 3.3 ta nhận thấy nồng độ khí $\mathrm{CO}$ trong máu bệnh nhân giảm rõ rệt chỉ sau quá trình điêu trị, nồng độ khí CO sau 7 ngày điều trị giảm từ $15,23 \pm 2,18$ ngày đâu tiên xuống chỉ còn $13,56 \pm 2,56$ và sau 28 ngày chỉ số này chỉ còn $7,14 \pm 5,24$. Kết quả này có ý nghĩa thống kê với $p$ sau 7 ngày và trước sau điều trị p D0-D28 $<0.05$.

3.4. Đánh giá kết quả dựa trên nồng độ $\mathrm{CO}$ Bảng 3.4. Đánh giá kết quả điều trị

\begin{tabular}{|c|c|c|}
\hline Kết quả & n & Phân trăm \\
\hline Tốt & 80 & 57,2 \\
\hline Khá & 23 & 16,4 \\
\hline Không kết quả & 37 & 26,4 \\
\hline Tống số & 140 & $100 \%$ \\
\hline
\end{tabular}

Nhận xét: Kết quả cai nghiện thuốc lá bằng nhĩ áp kết hợp phương pháp luyện thở dưỡng sinh Nguyễn Văn Hưởng và tư vấn đạt tỷ lệ $57,2 \%$ tốt, $16,4 \%$ khá và $26.4 \%$ không kết quả.

3.5. Kết quả tái khám sau khi kết thúc điêu trị.

Bảng 3.5 Kêt quả sau khi kêt thúc đợt điều trị

\begin{tabular}{|c|c|c|c|c|}
\hline \multirow{2}{*}{ Kết quả Thời gian } & \multicolumn{2}{|c|}{ D60 } & \multicolumn{2}{c|}{ D90 } \\
\cline { 2 - 5 } & $\mathbf{n}$ & $\mathbf{\%}$ & $\mathbf{n}$ & $\mathbf{\%}$ \\
\hline Không còn hút thuốc & 103 & 73,6 & 101 & 72,1 \\
\hline Hút thuốc lại & 37 & 26,4 & 39 & 27,9 \\
\hline
\end{tabular}

Nhận xét: Theo dõi sau 2 tháng điêu trị kết quả cai nghiện không thay đổi với tỉ lê người không còn hút thuốc là $73,6 \%$, người còn hút là $26,4 \%$, sau 3 tháng điều trị có 2 đối tượng hút thuốc trở lại vì vậy tỉ lệ người không còn hút thuốc giảm xuống còn $72,1 \%$.

3.5. Tác dụng không mong muốn của phương pháp can thiệp. Theo dõi trong quá trình nghiên cứu của chúng tôi cho thấy khi sử dụng phương pháp điều trị bằng nhĩ áp kết hợp phương pháp luyện thở dưỡng sinh Nguyễn Vằn Hưởng và tư vấn trên bệnh nhân cai nghiện thuốc lá không ghi nhận có các tai biến xảy ra.

\section{BÀN LUẬN}

4.1 Cải thiện triệu chứng lâm sang. Kết quả bảng 3.1 cho thẩy phương pháp hỗ trợ cai nghiện thuốc lá bằng nhĩ áp kết hợp phương pháp luyện thở dưỡng sinh Nguyễn Văn Hưởng và tư vấn có thể cải thiện được các triệu chứng lâm sàng do hội chứng cai gây ra như: thèm thuốc, lo lắng, căng thẳng, cáu gắt, giảm tập trung.... Sau 7 ngày điều trị hố trợ cai nghiện thuốc lá, đây là thời kỳ khó khăn nhất của người cai, nồng độ nicotin trong máu bắt đầu giảm xuống, các triệu chứng khó chịu của hội chứng cai bắt đầu biểu hiện nhiều hơn: tỷ lệ thèm thuốc tăng đến $99,3 \%$, căng thẳng cũng chiếm tî lệ cao với $45 \%$, giảm tâp trung $35,71 \%$, cáu gắt $13,57 \%$, các triệu chứng khác cũng tăng như như lo lắng, cáu gắt, mất ngủ... ngoài ra đến ngày thứ 7 đã bắt đầu xuất hiện triệu chứng tăng cân, ở người cai nghiện thuốc lá nguyên nhân tăng cân thường do nicotin làm tăng trao đổi chất, giảm thèm ăn.... Từ sau ngày thứ 14 , người cai nghiện bắt đầu quen dần với sự sụt giảm nồng độ nicotin trong máu khi áp dụng phương pháp cai thiệp thì các triệu chứng cai bắt đâu giảm ở cả hai nhóm, đến ngày thứ 28 thì các triệu chứng giảm rõ rệt: tỉ lệ thềm thuốc ở nhóm nghiên cứu còn $25,71 \%$, giảm tập trung còn $2,14 \%$, và tăng cân còn $8,57 \%$, các triệu 
chứng khác như cáu gắt, lo lắng, căng thẳng đau đầu, ho, ngứa họng ... không còn.

4.2. Thay đổi mạch, huyết áp và nông độ khí CO: Cai nghiện thuốc lá bằng nhĩ áp kết hợp phương pháp luyện thở dưỡng sinh Nguyễn Vằn Hưởng và tư vấn có thể làm giảm triệu chứng của hội chứng cai cho bệnh nhân, nhưng không làm thay đổi các chỉ số mạch, huyết áp sau quá trình điều trị.

Kết quả bảng 3.2 Nhịp tim và huyết áp trước và sau điều trị đều nằm trong khoảng giá trị trung bình: nhịp tim trước khi cai nghiện là 70,76 $\pm 10,48$ lần/ phút và sau khi cai nghiện là $70,7 \pm$ 9,39 lần/ phút, huyết áp tối đa trước cai là $119,89 \pm 8,27 \mathrm{mmHg}$ và sau cai là $119,11 \pm$ $7,87 \mathrm{mmHg}$, huyết áp tối thiểu trước cai là 72,96 $\pm 6,59 \mathrm{mmHg}$ và sau cai là $72,57 \pm 6,85 \mathrm{mmHg}$. Kết quả về sự thay đổi nhịp tim và huyết áp trước và sau điều trị không có ý nghĩa thống kê với p D0- D28 > 0.05 .

Kết quả bảng 3.3 ta thấy nồng độ khí $\mathrm{CO}$ trong hơi thở bệnh nhân giảm rõ rệt trong quá trình điều trị. Chỉ sau 07 ngày điều trị, nồng độ khí CO giảm xuống từ 15,23 $\pm 2,18$ ngày đâu tiên xuống còn $13,56 \pm 2,56$ và đến ngày 28 thì chỉ số này chỉ còn $7,14 \pm 5,24$. Kết quả này có ý nghĩa thống kê trước với $p$ sau 7 ngày và $p$ trước sau điều trị đều $<0.05$.

4.3. Kết quả điêuu trị cai nghiện thuốc lá. Hiệu quả cai nghiện thuốc lá bằng phương pháp Nhĩ áp kết hợp phương pháp luyện thở dưỡng sinh Nguyễn Văn Hưởng và tư vấn đạt tỷ $57,2 \%$ tốt, $16,4 \%$ khá và $26.4 \%$ không kêt quả. Điều này cho thấy những trường hợp nếu có quyết tâm cai nghiện cao cùng với việc tuân thủ điều trị thì kết quả cai nghiện rất tốt thể hiện qua sự cải thiện nông độ đo khí $C O$ và các triệu chứng của hội chứng cai như thèm thuốc, lo lắng, căng thẳng, cáu gắt...

4.4. Tác dụng không mong muốn của phương pháp can thiệp. Theo dõi trong quá trình nghiên cứu của chúng tôi không ghi nhận có các tác dụng không mong muốn như choáng, mẩn ngứa tại vị trí miếng dán nhĩ áp, nhiễm trùng hay bất kỳ tai biến nào khác xảy ra.

4.5. Kết quả tái khám sau khi kết thúc đợt điều trị. Tại nghiên cứu của chúng tôi bệnh nhân được theo dõi thêm 2 tháng và 3 tháng sau điều trị, kết quả sau điều trị 2 tháng không có sự thay đổi với tỉ lệ là $73.6 \%$ người không còn hút thuốc, sau điều trị 3 tháng có 2 đối tượng hút thuốc trở lại vì vậyy tỉ lệ người không còn hút thuốc giảm xuống còn $72,1 \%$. Điều này cho thấy sau khi kết thúc điều trị kết quả cai nghiện vẫn còn tồn tại.

\section{KẾT LUÂN}

5.1. Nhĩ áp kết hợp phương pháp luyện thở dưỡng sinh Nguyễn Văn Hưởng và tư vấn có tác dụng tốt trong điêu trị Hội chứng cai trong cai nghiện thuốc lá:

- Nhĩ áp kêt hợp phương pháp luyện thở dưỡng sinh Nguyễn Văn Hưởng và tư vấn có tác dụng cải thiện các triệu chứng của hội chứng cai như: thèm thuốc, lo lắng, cáu gắt, căng thẳng, giảm tập trung, mất ngủ, tăng cân...

- Nhĩ áp kết hợp phương pháp luyện thở dưỡng sinh Nguyễn Văn Hưởng và tư vấn có tác dụng làm giảm hàm lượng $\mathrm{CO}$ trong hơi thở của bệnh nhân sau cai nghiện thuốc lá.

- Hiệu quả cai nghiện thuốc lá của phương pháp Nhĩ áp kết hợp phương pháp luyện thở dưỡng sinh Nguyễn Văn Hưởng và tư vấn đạt kết quả thành công là $57,2 \%$ tốt, $16,4 \%$ khá và 26.4\% không kêt quả

- Sau khi kết thúc điều trị kết quả cai nghiện vẫn còn: sau 2 tháng điều trị kết quả cai nghiện không thay đổi với tỉ lệ người không còn hút thuốc là $73,6 \%$, sau 3 tháng điều trị tỉ lệ người không còn hút thuốc là $72,1 \%$.

5.2. Tác dụng không mong muốn trên lâm sàng: Trong quá trình nghiên cứu, phương pháp Nhĩ áp kết hợp phương pháp luyện thở dưỡng sinh Nguyễn Văn Hưởng và tư vấn không ghi nhận có tác dụng không mong muốn trên lâm sàng.

\section{TÀI LIÊU THAM KHẢO}

1. World Health Organization(2019). Tobaco. 26 July 2019 https://www.who.int/news-room/factsheets/detail/tobacco.

2. Bộ Y Tế, WHO (2015). Điều tra toàn cầu về hút thuốc lá ở người trưởng thành tại Việt Nam (Global Adult Tobacco survey - GATS).

3. National Toxicology Program(2016). TobaccoRelated Exposures. In: Report on Carcinogens. Fourteenth Edition.U.S. Department of Health and Human Services, Public Health Service, National Toxicology Program, 2016.

4. U.S. Department of Health and Human Services (2010). How tobacco smoke cause disease. The biology and behavioral basis for smoking - attributable disease.

5. U.S. Department of Health and Human Services (2015). The health consequences of smoking - 50 years of progress.

6. American Psychiatric Association. Diagnostic and Statistical Manual (1994)

7. Khoa Châm cứu dưỡng sinh, Bệnh viện $Y$ học cổ truyên Trung Ương (2005), Dưỡng sinh thực hành, tr. 39,40.

8. Yves Martínet et al (2007). Le traitement de la dépendance au tabac. Guide pratique. 